Небытова Лилия Анатольевна, Катренко Марина Васильевна, Савин Денис Игоревич, Сасин Александр Александрович

\title{
ИСПОЛЬЗОВАНИЕ ТЕХНОЛОГИИ ДОПОЛНЕННОЙ РЕАЛЬНОСТИ КАК СРЕДСТВА ПОВЫШЕНИЯ ЭФФЕКТИВНОСТИ УЧЕБНО-ТРЕНИРОВОЧНОГО ПРОЦЕССА ПО ЛЕГКОЙ АТЛЕТИКЕ ДЕТЕЙ С СУРДОЛОГИЧЕСКИМИ НАРУШЕНИЯМИ
}

Актуальность темы исследования обусловлена структурными особенностями построения спортивной тренировки спортсменов с сурдологическими нарушениями. Применение информационныхх технологий в учебно-тренировочном прочессе по легкой атлетике детей с наруиениями слуха позволяет интенсифицировать усвоение техники движений. Результаты использования (AR-) технологии выразилась в положительных изменениях по всем исследуемым критериям физической подготовленности детей и могут быть рекомендованы к работе не только с глухими и слабослыпиаицми спортсменами, но и со спортсменами с другими ограничениями в здоровье.

Ключевые слова: сурдологические наруиения, инфориационные технологии, дополненная реальность, AR-технология, учебно-тренировочный процесс, физические кондици.

Lilia Nebytova, Marina Katrenko, Denis Savin, Alexander Sasin THE APPLICATION OF THE TECHNOLOGY OF AUGMENTED REALITY TO IMPROVE THE EFFECTIVENESS OF EDUCATIONAL AND TRAINING PROCESS

IN TRACK AND FIELD ATHLETICS FOR HEARING-IMPAIRED CHILDREN

The relevance of the present research stems from the fact that the structuring of sports activity of hearing-impaired athletes has objective features. The use of IT technologies in educational and training process can be very helpful for the hearing-impaired children to enhance their learning of the movement techniques in track and field athletics. The results of using of AR technology have shown considerable positive changes in overall test criteria with hearing-impaired athletes. Accordingly, the use of AR technology might as well be recommended for working with athletes having other health limitations.

Key words: hearing impairment, information technologies, augmented reality, AR-technology, educational and training process, physical condition.

Bведение / Introduction. Внедрение информационных технологий в жизнедеятельность человека неуклонно возрастает. Одним из направлений является образование, информатизация которого тесно связана с информатизацией общества. Следует подчеркнуть, что требованием современного общества выступает раскрытие и реализация потенциала каждого человека, в том числе и инвалидов. Но практика показывает, что в силу физических и психических особенностей инвалидов их социализация происходит гораздо сложнее [8].

Специализированное учреждение Организации Объединённых Наций по вопросам образования, науки и культуры ЮНЭСКО выступает инициатором программы Всемирного движения «Образование для всех». Его конечная цель - инклюзивное образование [1; 10]. На сегодняшний день значительную часть группы высокого риска по различным патологиям и сложным нарушениям в развитии составляют глухие и слабослышащие. У данной категории лиц речь не участвует в процессе решения наглядных задач, ограничен объем внешней информации, отсутствует внутренняя речь и словесное опосредование, что вызывает снижение восприятия, мышления, памяти, воображения и всей познавательной деятельности в целом [2]. 
Образовательный процесс для лиц с нарушениями слуха выстраивается с учетом некоторых особенностей нервной системы, а именно фрагментарности и замедленности слухового восприятия, искаженности и несформированности словесных представлений, связанных с сенсорной звуковой деривацией [9]. Для облегчения коммуникационного общения в занятиях в основном применяются визуальные методы обучения и наглядные способы передачи информации, в том числе и о выполнении предстоящего действия или движения: плакаты, фото, видеопоказ и т. д.

Одной из проблем лиц с ограниченными возможностями, независимо от их физических, психических, интеллектуальных, культурно-этнических, языковых и иных особенностей, являются колоссальные трудности в деятельности, связанной с двигательной активностью. Поэтому у глухих уровень физического развития более низкий, чем у людей, не имеющих отклонений в состоянии здоровья [3]. Тем не менее именно физическая культура и спорт - та область, в которой люди с сурдологическими нарушениями не чувствуют себя ущемленными. Кроме того, она имеет в данном случае системообразующее значение, так как посредством спортивной деятельности можно обеспечить не только коррекцию отклонений, но и достичь необходимого уровня физических кондиций. В спорте правила соревнований нивелируют невозможность общения глухих и слабослышащих со всеми остальными людьми, потому что они одинаковы для всех участников [9].

Занятия спортом с данным контингентом имеют как общие, так и свои специфические (коррекционные) задачи. Решение задач первого направления заключается в обучении двигательным действиям и в сообщении знаний в области спортивной тренировки, второго - в исправлении нарушений и компенсации деятельности всех физиологических систем организма, что определяет подбор педагогических технологий [4].

За основу обеспечения учебно-тренировочного процесса детей с сурдологическими нарушениями нами были взяты информационные технологии. При этом проявление интереса юных спортсменов, обусловленного поначалу технологической стороной используемых электронных средств, способствовало в дальнейшем росту интереса к содержанию теоретических и методических аспектов избранного вида спорта.

Maтериалы и методы/ Materials and methods. Исследование, проводилось с детьми ГКОУ «Специальная (коррекционная) общеобразовательная школа-интернат № 36 г. Ставрополя». Для обоснования использования технологии дополненной реальности как средства повышения эффективности учебно-тренировочного процесса по легкой атлетике детей в возрасте 7-10 лет (первый год обучения) с сурдологическими нарушениями были сформированы две группы спортсменов, экспериментальная и контрольная, по пять человек в каждой.

По особенностям организации, содержания и доказательной логике проводимый эксперимент относился к исследованию преобразующего характера. Учебные занятия в контрольной группе велись по общепринятой методике программы начального этапа обучения. Отличие организации работы в экспериментальной группе состояло в том, что на занятиях использовалась технология дополненной реальности (AR-). На основе существующего в современной науке анализа дидактических возможностей современных информационных технологий и средств $[5 ; 11 ; 12]$, а также учета особенностей физического и психомоторного развития ребенка, по нашему мнению, именно она позволяет значительно расширить возможности учебно-тренировочного процесса.

AR-технология (англ. Augmented reality, AR - расширенная реальность) означает введение в поле восприятия любых сенсорных данных с целью дополнения сведений об окружении и улучшения восприятия информации [6]. Дополненная реальность дает возможность посредством компьютерных технологий наложить изображение, текст, видео- и аудиокомпоненты на существующее изображение или пространство. Полученная таким образом дополнительная информация считывается с маркера всевозможными цифровыми устройствами, такими как смартфоны, планшеты, очки, AR-шлемы и др. В роли маркера выступает любой графический визуальный объект, 
на который с использованием специальных программных средств добавляются виртуальные объекты различных форматов [7]. В нашем случае в роли маркера использовался QR-code (информация), под которым зашифрованы темы изучаемого материала.

С учетом специфических особенностей занимающихся тематические разработки каждого тренировочного занятия создавались целенаправленно для конгретной задачи или имели комплексное назначение. Периодизация учебного процесса носила условный характер, основное внимание уделялось освоению подводящих к рассматриваемому виду спорта упражнений, разносторонней физической и функциональной подготовке с использованием главным образом средств ОФП.

Как наиболее эффективный для этой возрастной категории за основу был взят спортивно-игровой метод, предусматривающий, особенно в первые два года обучения, широкое применение специализированных игровых комплексов и тренировочных заданий (эстафеты, подвижные игры, сюжетные игровые композиции, круговая форма организации занятия и т. д.). Кроме того, использовались методы подводящих упражнений, раздельного и целостного разучивания упражнений, позволяющих одновременно с использованием разносторонней физической подготовкой подвести занимающихся к пониманию сути легкой атлетики как вида спорта.

Управляя объектами AR- за счет доступа в режиме онлайн, тренер или спортсмен, «оживляли» статичные страницы материала по конкретной теме программы («Развитие физических качеств», «Обучение технике прыжка в длину с места», «Закрепление навыка метания малого мяча» и пр.), перемещая их, поворачивая, изменяя масштаб, рассматривая с разных сторон. Это позволило спортсменам экспериментальной группы видеть элементы правильного выполнения различных упражнений, определять собственные ошибки.

Результаты и обсуждение/Results and discussion. Согласно полученным результатам исследования, технология дополненной реальности (AR-) существенно модернизирует спортивную деятельность, так как её применение позволяет продемонстрировать с любой степенью детализации выполняемые действия и упражнения различного характера. Для оценки эффективности использования AR-технологии в учебно-тренировочном процессе были применены обязательные переводные тесты: бег на 100 м, бег на 20 м, прыжок в длину с места, прыжки на скакалке за 30 сек. В контрольной группе при сравнении начальных и конечных показателей значительных изменений не констатировалось. В то время как в экспериментальной наблюдался их существенный прирост. В видах испытаний, требующих проявление быстроты, ловкости и скоростно-силовых качеств, средние результаты претерпели достоверные изменения $(\mathrm{P}<0,001)$. Это объясняется целенаправленным применением технологии дополненной реальности, которая погружала юных спортсменов в игровую среду, предоставляя им возможность получать необходимую информацию об элементах техники движений и затем демонстрировать свои результаты на соревнованиях.

Заключение / Conclusion. Речевая недостаточность глухих и слабослышащих детей, затрудняет восприятие информации. Технология дополненной реальности придает процессу тренировки устойчивый и целенаправленный характер. В работе с данным контингентом это действительная жизнеспособная альтернатива традиционному подходу в спортивной тренировке. Её применение способствует интенсификации учебно-тренировочного процесса, коррекции двигательных нарушений, осмыслению двигательной и речевой информации, активизации интеллектуальной деятельности; также служит импульсом к развитию пространственного мышления, позволяет овладевать учебно-познавательными, информационными и коммуникативными компетенциями.

Положительным моментом в использовании дополненной реальности является её интерактивность, так как полностью исчезает потребность в приобретении стендов, плакатов, досок и прочих наглядных пособий. 
Проведенное нами исследование доказывает, что технология дополненной реальности является средством повышения эффективности учебно-тренировочного процесса по легкой атлетике детей с сурдологическими нарушениями.

Разработки исследования могут быть рекомендованы для практического применения как в работе с детьми ОВ3, так и при составлении учебных программ, программ повышения квалификации и учебно-методических пособий.

\section{ЛИТЕРАТУРА И ИНТЕРНЕТ-РЕСУРСЫ}

1. Аналитическая записка. ИКТ для инклюзивного образования / Институт ЮНЕСКО по информационным технологиям в образовании. - 2010. - С. 1.

2. Богданова Т. Г. Сурдопсихология: учебное пособие для студ. высш. пед. учеб. заведений / Т. Г. Богданова. Москва : Академия, 2002. - 203 с.

3. Выготский Л. С. Основы дефектологии / Л. С. Выготский. - Санкт-Петербург : Лань, 2003. - 654 с.

4. Дополнительная предпрофессиональная программа «Спорт глухих». - Воронеж, 2016. - С. 59-62.

5. Зильберман, Н. Н. Возможности использования приложений дополненной реальности в образовании / Н. Н. Зильберман, В. А. Сербин // Открытое и дистанционное образование. - 2014. - № 4 (56). C. $28-34$.

6. Козин В. В. Методы и приемы дополненной реальности в тактико-технической подготовке спортсменов командно-игровых видов спорта / В. В. Козин, Д. Ю. Витман // Современные наукоемкие технологии. - 2018. - № 5. - С. 199-203.

7. Куликова Т. А. Аr-технология в образовательном процессе вуза / Т. А. Куликова, Н. А. Поддубная // Вестник ТвГУ. Серия «Педагогика и психология), - 2018. - № 4. - С. 252-257.

8. Небытова Л. А. Физическая культура и спорт : интеграция науки и практики / Л. А. Небытова, A. М. Чибисов // Материалы XV Международной научно-практической конференции. - Ставрополь : Изд-во СКФУ, 2018. - С. 200-202.

9. Степаненко Д. И. Организационно-методические рекомендации проведения тренировочных занятий у легкоатлетов с нарушениями слуха / Д. И. Степаненко, А. Ю. Печко // Прикладная спортивная наука. - 2016. - № 2 (4) - - C. 37-40.

10. The distribution of the level of disability. - World Bank, 2007.

11. Diegmann P. Benefits of Augmented Reality in Educational Environments - A Systematic Literature Review / P. Diegmann, M. Schmidt-Kraepelin, S. van den Eynden, and D. Basten // Proceedings of the 12th International Conference on Wirtschaftsinformatik (WI). - 2015. - Pp. 1542-1556.

12. Wu H.-K., Lee S., Chang H.-Y., Liang, J.-C. Current Status, Opportunities and Challenges of Augmented Reality in Education / H.-K. Wu, S. Lee, H.-Y. Chang, J.-C. Liang // Computers \& Education 62, 2013. Pp. 41-49.

\section{REFERENCES AND INTERNET RESOURCES}

1. Analiticheskaja zapiska. IKT dlja inkljuzivnogo obrazovanija / Institut JuNESKO po informacionnym tehnologijam v obrazovanii. 2010. - S. 1 .

2. Bogdanova T. G. Surdopsihologija: Uchebnoe posobie dlja stud. vyssh. ped. ucheb. Zavedenij / T. G. Bogdanova. - Moskva : Akademija, 2002. - 203 s.

3. Vygotskij L. S. Osnovy defektologii / L. S. Vygotskij. - Sankt-Peterburg : Lan', 2003. $654 \mathrm{~s}$.

4. Dopolnitel'naja predprofessional'naja programma «Sport gluhih». - Voronezh. 2016. - S. 59-62.

5. Zil'berman N. N. Vozmozhnosti ispol'zovanija prilozhenij dopolnennoj real'nosti $\mathrm{v}$ obrazovanii / N. N. Zil'berman, V. A. Serbin // Otkrytoe i distancionnoe obrazovanie. - 2014. - № 4 (56). - S. $28-34$.

6. Kozin V. V. Metody i priemy dopolnennoj real'nosti $\mathrm{v}$ taktiko-tehnicheskoj podgotovke sportsmenov komandno-igrovyh vidov sporta / V. V. Kozin, D. Ju. Vitman // Sovremennye naukoemkie tehnologii. 2018. - № 5. - S. 199-203.

7. Kulikova T. A. Ar-tehnologija v obrazovatel'nom processe vuza / T. A. Kulikova, N. A. Poddubnaja // Vestnik TvGU. Serija «Pedagogika i psihologija». 2018. № 4. S. $252-257$. 
8. Nebytova L. A. Fizicheskaja kul'tura i sport: integracija nauki i praktiki / L. A. Nebytova, A. M. Chibisov // Materialy XV Mezhdunarodnoj nauchno-prakticheskoj konferencii. - Stavropol': Izd-vo SKFU, 2018. 285 s. C. $200-202$.

9. Stepanenko, D. I. Organizacionno-metodicheskie rekomendacii provedenija trenirovochnyh zanjatij u legkoatletov s narushenijami sluha / D. I. Stepanenko, A. Ju. Pechko // Prikladnaja sportivnaja nauka. 2016. - № 2 (4). - S. 37-40.

10. The distribution of the level of disability. - World Bank, 2007.

11. Diegmann, P. Basten Benefits of Augmented Reality in Educational Environments - A Systematic Literature Review / P. Diegmann, M. Schmidt-Kraepelin, S. van den Eynden, and D. // Proceedings of the 12th International Conference on Wirtschaftsinformatik (WI). - 2015. - S. 1542-1556.

12. Wu H.-K. Current Status, Opportunities and Challenges of Augmented Reality in Education / H.-K. Wu, S. Lee, H.-Y. Chang, J.-C. Liang // Computers \& Education 62, 2013. R. 41 - 49.

\section{СВЕДЕНИЯ ОБ АВТОРАХ}

Небытова Лилия Анатольевна, кандидат психологических наук, доцент, доцент кафедры физической культуры и здоровьесбережения, государственное бюджетное учреждение дополнительного профессионального образования «Ставропольский краевой институт развития образования, повышения квалификации и переподготовки работников образования», г. Ставрополь. E-mail: nebitova.lilia@yavdex.ru

Катренко Марина Васильевна, кандидат педагогических наук, доцент, кафедра физической культуры для технических специальностей, факультет физической культуры, институт образования и социальных наук, федеральное государственное автономное образовательное учреждение высшего образования «Северо-Кавказский федеральный университет», г. Ставрополь. E-mail: mkatrenko69@bk.ru

Савин Денис Игоревич, кандидат педагогических наук, кафедра физической культуры для технических специальностей, факультет физической культуры, институт образования и социальньх наук, федеральное государственное автономное образовательное учреждение высшего образования «Северо-Кавказский федеральный университет». E-mail: savindenis1978@mail.ru

Сасин Александр Александрович, старший преподаватель кафедры физического воспитания Московского государственного технического университета им. Н. Э. Баумана, г. Москва. E-mail: aleksandersasin@ mail.ru

\section{INFORMATION ABOUT AUTHORS}

Liliya Nebytova, Candidate of Psychological Sciences, Associate Professor, Associate Professor, Department of Physical Culture and Health Saving, State Budgetary Institution of Continuing Professional Education "Stavropol Territory Institute for the Development of Education, Continuing Education and Retraining of Education Workers", Stavropol. E-mail: nebitova.lilia@yavdex.ru

Marina Katrenko, Candidate of Pedagogical Sciences, Associate Professor, Department of Physical Education for Technical Specialties, Faculty of Physical Education, Institute of Education and Social Sciences, Federal State Autonomous Educational Institution of Higher Education «North Caucasian Federal University». E-mail: mkatrenko69@bk.ru

Denis Savin, Candidate of Pedagogical Sciences, Department of Physical Culture for Technical Specialties, Faculty of Physical Education, Institute of Education and Social Sciences, Federal State Autonomous Educational Institution of Higher Education «North Caucasus Federal University». E-mail: savindenis1978@mail.ru

Alexander Sasin, Senior Lecturer, Department of Physical Education, Moscow State Technical University N. E. Bauman, Moscow. E-mail: aleksandersasin@mail.ru 